\section{JDR EDITOR-IN-CHIEF NAMED}

The International and American Associations for Dental Research (IADR/AADR) have announced that William Giannobile has been selected as the Editor-in-Chief of the Journal of Dental Research.

Professor Giannobile will begin his term in April 2010, and will succeed Anthony 'Tony' Smith, who has served as the JDR Editor-in-Chief since 2004. The JDR Editor-in-Chief is responsible for the full range of editorial duties, including review and acceptance of manuscripts, in co-operation with Associate Editors, reviewers, and an Editorial Board.

Professor Giannobile is a William K and Mary Anne Najjar Endowed Professor of Dentistry and the Director of the Michigan Center for Oral Health Research at the University of Michigan School of Dentistry. He is also Professor of Biomedical Engineering at the University of Michigan College of Engineering.

IADR President David M Williams said 'Dr Giannobile comes to the JDR with an exceptional research and science background, and I'm certain he will continue the standard of excellence set by previous editors of the Journal.'

\section{VACANCY FOR EDITOR}

The British Society for Disability and Oral Health is looking for a new editor for the Journal of Disability and Oral Health. The post will become vacant in June 2010. Interested applicants should forward a letter of intent electronically, together with a CV, by 7 March 2010 to Dr Sue Greening, Chairperson, British Society for Disability and Oral Health, at sue.greening@wales.nhs.uk. Informal enquiries may be sent to the current editor, Professor June Nunn: june.nunn@dental.tcd.ie.

\section{ORAL HEALTH OF DISADVANTAGED GROUPS}

The All-Party Parliamentary Group (APPG) for Dentistry recently held its final meeting before the General Election. The meeting in the House of Commons focused on the oral health of disadvantaged groups.

An audience of cross-party MPs, Peers and stakeholders from across the dental profession heard about delivering dental care to the prison population and residents of care homes.

After an introduction by Charlotte Atkins, Labour MP for Staffordshire Moorlands and the Chair of the APPG for Dentistry, the meeting received presentations from three speakers. Judith Husband, BDA Executive Board Member and dentist at Bullingdon Community Prison, began by giving an insight into providing care in a prison and the unique challenges it presents to dentists and their teams.

Gill Heyes, of the Residential Oral Care Sheffield scheme, spoke about the pioneering work taking place in the city to deliver joined-up care to patients in residential care homes. This scheme has been heralded by the dental profession and was cited by the BDA's Oral Health Inequalities paper as an example of best practice when it was published last year.

Finally, senior dental nurse in Gloucester and President of the British Association of Dental Nurses, Sue Bruckel, highlighted her experience of providing care in prisons as well as the role that dental nurses and other dental care professionals can play in providing that care. A lively question and answer session with the MPs and Peers followed the speeches.

The APPG for Dentistry was established in December 2008 and acts as a focus for dental and oral health issues, raising the profile of dentistry in Parliament and highlighting the views of both the profession and patients. The BDA is the elected secretariat to the Group.

It aims to act as a focus for dental and oral health issues, raising the profile of dentistry and highlighting the views of patients and practitioners and is supported by the BDA, GDC, BDTA, DPA and DLA.

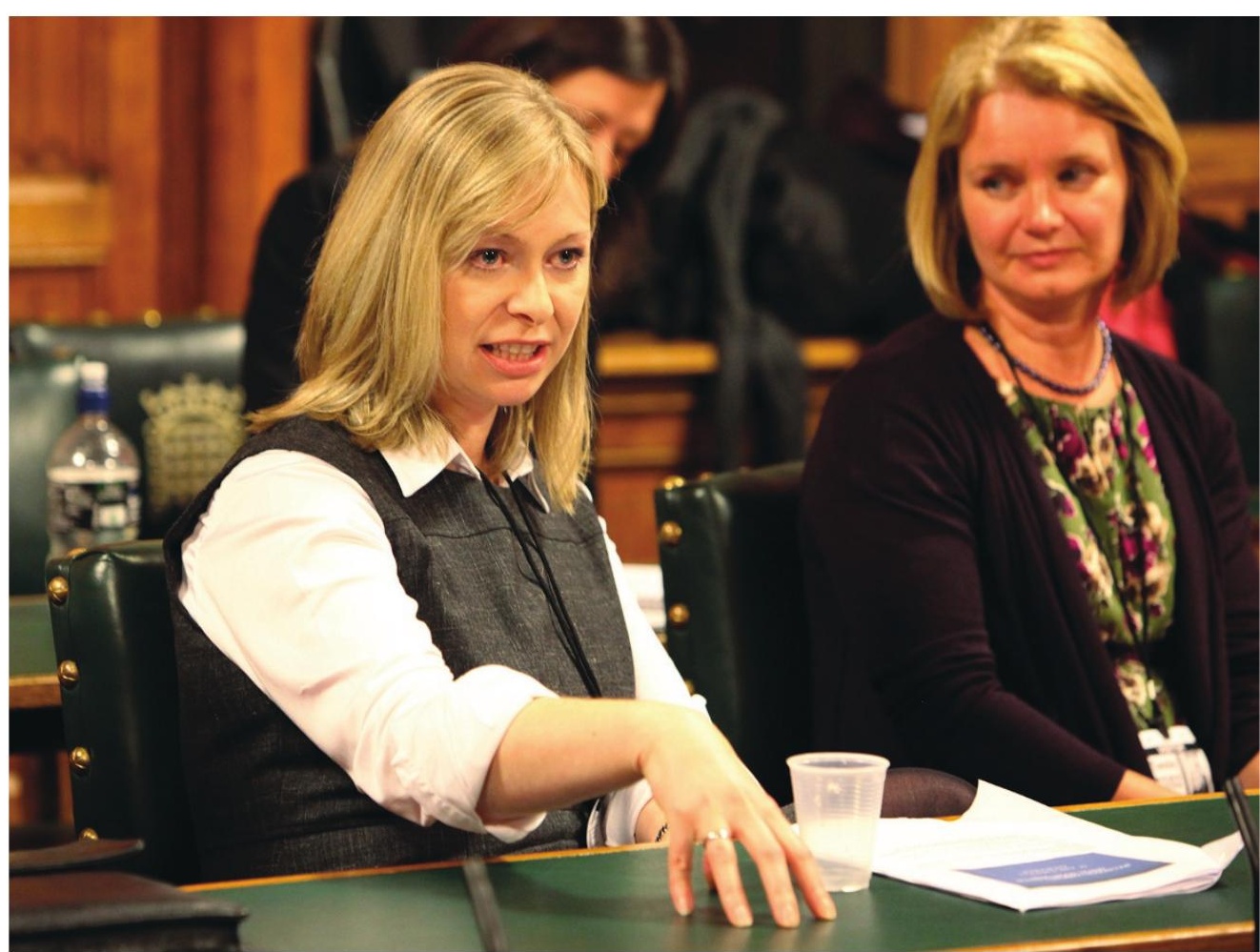

BDA Executive Board member Judith Husband (left), speaking as a prison dentist, next to Gill Heyes of the Residential Oral Care Sheffield scheme 